\title{
The utility and safety of temporary pacing wires in postoperative patients with congenital heart disease
}

Jose M. Moltedo, MD, , ad Geoffrey L. Rosenthal, MD, ${ }^{b}$ Jeffrey Delaney, MD, ${ }^{\text {,dd }}$ Dennis Mello, MD, d,f

and Christopher S. Snyder, MD, d,e Buenos Aires, Argentina, Cleveland, Ohio, Durham, NC,

New Haven and Hartford, Conn, and New Orleans, La

A rrhythmias constitute a common complication after cardiovascular surgery (CVS) in pediatric patients. ${ }^{1-3}$ Pacing wires are helpful in the differentiation and treatment of supraventricular, ventricular, and sinus tachycardia. The purpose of this study was to determine (1) whether pacing wires are useful in the diagnosis and treatment of early postoperative arrhythmias, (2) whether any factors exist to predict patients who benefit from their placement, and (3) the complications associated with their placement, use, or removal.

\section{Clinical Summary}

A single-center, institutional review board-approved, prospective observational study was performed. Inclusion criteria were as follows: patient age of less than 18 years and CVS between September 2000 and March 2003. Exclusion criteria were a patent ductus arteriosus ligation or coarctation of the aorta repair because wires were not placed. Data collected included cardiopulmonary bypass $(\mathrm{CPB})$ and aortic crossclamp (AXC) times, pacing wire placement and location, use of pacing wires, and complications. Before chest tube removal and transfer from the intensive care unit, wires were removed by a pediatric cardiology fellow.

The Student test and $\chi$ analysis, along with simple and multiple logistic regression analysis, were used to make comparisons.

A total of 209 patients met the inclusion criteria: 170 (81\%) having pacing wires, $159(93.5 \%)$ having atrial and ventricular wires, $10(5.9 \%)$ having ventricular wires, and 1 having atrial pacing wires. Wires were used in 59 (35\%) patients: 33 for diagnostic purposes, 11 for therapeutic purposes, and 15 for both purposes.

From the Section of Pediatric Cardiology, ${ }^{a}$ FLENI Institute, Buenos Aires, Argentina; the Division of Pediatrics, Section of Pediatric Cardiology, ${ }^{b}$ Cleveland Clinic Foundation, Cleveland, Ohio; the Division of Pediatrics, Section of Pediatric Cardiology, ${ }^{\mathrm{c}}$ Duke University, Durham, NC; the Division of Pediatrics, Section of Pediatric Cardiology, ${ }^{\mathrm{d}}$ Yale University School of Medicine, New Haven, Conn; and the Division of Pediatrics, Section of Pediatric Cardiology, ${ }^{\mathrm{e}}$ Ochsner Clinic Foundation, New Orleans, La; Section of Pediatric Cardiovascular Surgery, Connecticut Children's Hospital, ${ }^{\mathrm{f}}$ Hartford, Conn.

Received for publication Nov 27, 2006; revisions received Jan 2, 2007; accepted for publication Jan 8, 2007

Address for reprints: Christopher S. Snyder, MD, Ochsner Clinic Foundation, 1514 Jefferson Highway, New Orleans, LA 70121 (E-mail: csnyder@ ochsner.org).

J Thorac Cardiovasc Surg 2007;134:515-6

$0022-5223 / \$ 32.00$

Copyright $\odot 2007$ by The American Association for Thoracic Surgery doi:10.1016/j.jtcvs.2007.01.091
Comparisons between group 1, those with pacing wires, and group 2, those without pacing wires, found a significant difference in CPB time (123.8 vs 46.1 minutes) and AXC time (59.5 vs 18.5 minutes, $P<.0001)$.

Splitting group 1 into those who used their pacing wires (group 1A) versus those who did not (group 1B), direct relationships were found between longer AXC time (81.4 vs 47.9 minutes, $P<$ $.0001)$ and CPB time (151.3 vs 109.1 minutes, $P<.0006)$. Further analysis of group 1A, dividing it into those who used the wires for therapeutic, diagnostic, or both therapeutic and diagnostic purposes versus group $1 \mathrm{~B}$ found that both $\mathrm{AXC}$ and $\mathrm{CPB}$ times increased (Table 1).

For every 10-minute increase in AXC time, the odds of therapeutic use of the pacing wires increased by $27 \%$ (95\% confidence interval $[\mathrm{CI}], 16 \%-40 \%$ ). For each 10-minute increase in CPB, the odds of therapeutic use of the pacing wires increases by $13 \%(95 \%$ CI, 7\%-20\%). When AXC and CPB times were entered into the

TABLE 1. Comparisons between groups

\begin{tabular}{|c|c|c|c|c|}
\hline & AXC & CPB & Mg & $\mathrm{Ca}$ \\
\hline \multicolumn{5}{|c|}{$\begin{array}{l}\text { Pacing wires }(n=170) \\
\text { no pacing wires }(n=59)\end{array}$} \\
\hline Group 1 & 59.5 & 123.8 & 1.5 & 4.78 \\
\hline Group 2 & 18.5 & 46.1 & 1.62 & 4.62 \\
\hline$P$ value & $<.0001$ & $<.0001$ & .004 & NS \\
\hline \multicolumn{5}{|l|}{ Use: group 1 patients } \\
\hline \multicolumn{5}{|l|}{ Group 1A (used; $n=59$ ), } \\
\hline \multicolumn{5}{|c|}{ Group 1B (unused; $n=112$ ) } \\
\hline Group 1A & 81.4 & 151.3 & 1.49 & 4.81 \\
\hline Group 1B & 47.9 & 109.1 & 1.51 & 4.77 \\
\hline$P$ value & $<.0001$ & .0006 & NS & NS \\
\hline \multicolumn{5}{|c|}{$\begin{array}{l}\text { Therapeutic ( } \mathrm{n}=28) \text {, diagnostic } \\
\qquad(\mathrm{n}=48) \text {, both }(\mathrm{n}=17)\end{array}$} \\
\hline Therapeutic & 98.3 & 164.8 & 1.53 & 4.98 \\
\hline Group 1B/diagnostic & 51.5 & 115.6 & 1.5 & 4.76 \\
\hline$P$ value & $<.0001$ & .0007 & NS & NS \\
\hline Diagnostic & 86 & 159 & 1.47 & 4.83 \\
\hline Group 1B/therapeutic & 48.6 & 109.7 & 1.51 & 4.77 \\
\hline$P$ value & $<.0001$ & .0003 & NS & NS \\
\hline Therapeutic & 98.3 & 164.8 & 1.53 & 4.91 \\
\hline Diagnostic & 65.7 & 139 & 1.46 & 4.74 \\
\hline$P$ value & .0213 & NS & NS & NS \\
\hline
\end{tabular}

Aortic crossclamp and cardiopulmonary bypass times are measured in minutes. Magnesium levels are measured in $\mathrm{mg} / \mathrm{dL}$, and ionized calcium levels are measured in $\mathrm{mg} \%$. AXC, Aortic crossclamp; $C P B$, cardiopulmonary bypass; $M g$, magnesium; $C a$, calcium; $N S$, not significant. 
model simultaneously, only AXC time was an important predictor of therapeutic use of pacing wires.

In our group of patients, no complications related to the placement, use, or removal of wires was noted. The 95\% CI around the estimate of complication rate is $0 \%$ to $1.2 \%$. None of the patients in whom wires were not placed experienced an arrhythmia. The surgeons were able to predict with $100 \%$ accuracy the patients not requiring pacing wires but only $26 \%$ (59/170) of those patients who would.

\section{Discussion}

This study found the incidence of use of pacing wires to be equal to $26 \%$ for post-CVS pediatric patients. Of those operations in which pacing wires were placed, the percentage of use increased to $35 \%$, with more than half $(56 \%)$ for diagnostic purposes.

When analysis was performed to evaluate the need for pacing wires (diagnostic, therapeutic, or both), 2 predictors fell out: length of $\mathrm{AXC}$ and $\mathrm{CPB}$ time. When the group of patients with pacing wires was further analyzed, therapeutic and diagnostic versus all other, significantly longer AXC and CPB times were noted as predictors. When comparisons were made between pacing wires used for therapeutic and diagnostic purposes, the only difference was in the AXC time (98.3 vs 65.7 minutes).

Although this study does not determine patients who require pacing wires, it does provide some guidelines. Patients whose
AXC times, CPB times, or both are longer might benefit from placing pacing wires at the time of CVS. With each 10-minute increase in $\mathrm{AXC}$ or $\mathrm{CPB}$ time, a significant increase, $27 \%$ and $13 \%$, occurred in the therapeutic use of pacing wires. These findings, longer AXC and CPB times, might simply be variables of the surgical complexity of the case. Despite anecdotal reports of complications associated with pacing wires, no complications were noted with the placement, use, or removal in this study.

Patients with longer CPB and AXC times associated with more complicated surgical procedures have a significantly higher chance of requiring pacing wires for their postoperative management. In addition, their placement, use, and removal appear to be safe.

\section{References}

1. Pfammatter JP, Bachmann DCG, Wagner BP, et al. Early postoperative arrhythmias after open heart procedures in children with congenital heart disease. Pediatr Crit Care Med. 2001;2:217-22.

2. Valsangiacomo E, Schmid ER, Schupbach RW, et al. Early postoperative arrhythmias after cardiac surgery in children. Ann Thorac Surg. 2002;74:792-6.

3. Delaney J, Moltedo J, Dziura JD, et al. Early postoperative arrhythmias after cardiac surgery in children. J Thorac Cardiovasc Surg. 2006;131: 1296-1300.

\section{Hybrid approach as a bridging procedure to biventricular repair for aortic hypoplasia with ventricular septal defect in a 1720-g premature infant}

Pedro Betrián Blasco, MD, ${ }^{\text {a }}$ Josep Girona Comas, MD, ${ }^{\text {a }}$ Arturo Gonçalves Estella, MD, ${ }^{\text {b }}$ Queralt Ferrer Menduña, MD, ${ }^{a}$ María Concepción Céspedes Dominguez, MD, ${ }^{c}$ Joan Balcells Ramirez, MD, ${ }^{d}$ Begoña Manso García, MD, ${ }^{a}$ and Ferrán Gran Ipiña, MD, ${ }^{a}$ Barcelona, Spain

廿 ypoplastic left heart syndrome varies from mitroaortic atresia and a diminutive left ventricle to milder forms of mitroaortic stenosis with a reasonable-sized left ventricle.

\footnotetext{
From the Pediatric Cardiology and Hemodynamics Department, ${ }^{a}$ the Pediatric Cardiac Surgery Department, ${ }^{\mathrm{b}}$ Neonatology, ${ }^{\mathrm{c}}$ and the Pediatric Intensive Care Unit, "Valle de Hebrón Hospital," Barcelona, Spain.

Received for publication March 22, 2007; revisions received April 16, 2007; accepted for publication April 23, 2007.

Address for reprints: Pedro Betrián Blasco, $\mathrm{MD}, \mathrm{C} /{ }^{\mathrm{a}}$ Arquitecto Moragas 18 esc a $4^{\circ}$ 2a, Barcelona CP 08035, Spain (E-mail: pedrobetrian@yahoo.es).

J Thorac Cardiovasc Surg 2007;134:516-8

$0022-5223 / \$ 32.00$

Copyright $\odot 2007$ by The American Association for Thoracic Surgery doi:10.1016/j.jtcvs.2007.04.005
}

\section{Clinical Summary}

A female infant with fetal diagnosis of aortic atresia was born at 34 weeks of gestation weighing $1620 \mathrm{~g}$. At birth, echocardiography was carried out, showing a double-outlet right ventricle with great vessels side to side and aorta on the right and a large subpulmonary ventricular septal defect. The aorta was extremely hypoplastic, with a minimal anterograde blood flow. The aortic arch was also hypoplastic and filled with retrograde blood flow from the ductus. The left ventricle and mitral valve were in normal values. Prostaglandin $\mathrm{E}_{1}$ infusion was started.

When she was 25 days old, weighing $1720 \mathrm{~g}$, a median sternotomy was performed. First, pulmonary artery branches were banded at their origin (polytetrafluoroethylene bands,* diameter of $2.8 \mathrm{~mm})$. Next, two self-expandable stents $(6 \times 12 / 6 \times 18 \mathrm{~mm})$ were placed through the main pulmonary artery puncture to cover

*Gore-Tex band, registered trademark of W. L. Gore \& Associates, Inc, Newark, Del. 